\title{
Drainage Water Reuse under Water Scarcity
}

\author{
Aya Abd El-Moneim, Ahmed A. Hassan, Samia Abou El-Fotouh, Aiman El-Saadi, Ahmed \\ Abdallah
}

\begin{abstract}
Water resources management in arid regions and semi-arid such as Egypt is a continuous process for the achievement of rational use of the scarce water resources for the benefit of the national economy. Water scarcity in Egypt is a major challenge, which is annually increasing due to the high water demand of different sectors, while the share of Egypt from the Nile is fixed at 55.5 billion cubic meter (BCM). Non-conventional water resources, such as drainage water, are essential alternatives to improve the water use efficiency. In Nile Delta, a considerable number of reuse pump stations (RPSs) are distributed along the drains network already decades ago. But farmers are unofficially using small pumps to divert drainage water directly to their fields. The major concern in the reuse of agricultural drainage water is the build-up of salts. This research aims to assess the water balance in El-Behira governorate to reduce the negative impacts of water scarcity on the crop yield, soil deterioration, evapotranspiration. The model was calibrated using the water and agriculture data of the year 2014 which was used as a base year then it was validated using the data of year 2015. Two statistical goodness-of-fit coefficients [Nash-Sutcliffe model efficiency coefficient (NSE) and ratio of the root mean square error to the standard deviation of measured data (RSR)] were used to assess the re-calibration and validation of the model; where the results of the model showed good and very good performance with the observations. In addition; the water allocation of the study area was simulated by the SIWARE Model during the studied two years to assess the current water uses and soil conditions, while the results are visualized using Geographical Information System (GIS) as an essential tool for a decision support system. The simulation results indicated that the study area suffers from water stress that forces the farmers to unofficially reuse the drainage water. Electrical Conductivity (EC) of the unofficially reused water ranged between Medium and high hazard salinities that gives restrictions on the crop pattern, causes hygienic risks, and increases the pollution in the shallow aquifer.
\end{abstract}

Keywords: Drainage Water Management, SIWARE, EL-Behira Governorate, Water Scarcity, Reuse of Drainage Water

Revised Manuscript Received on February 15, 2020.

* Correspondence Author

Aya Abd El-Moneim *, National Water Research Center (NWRC), Egypt (Email: AyaEzz2007@yahoo.com)

Ahmed A. Hassan, Irrigation and Hydraulics Dept., Faculty of Engineering, Ain Shams University, Cairo, Egypt

(Email: ahmad9657@yahoo.co.uk)

Samia Abou El-Fotouh, Irrigation and Hydraulics Dept., Faculty of Engineering, Ain Shams University, Cairo, Egypt

(Email: eng_samia2004@yahoo.com )

Aiman El-Saadi, National Water Research Center (NWRC), Egypt (Emails: a.elsaadi@gmail.com )

Ahmed Abdallah, National Water Research Center (NWRC), Egypt (Emails: ah.abdullaah@gmail.com )

(C) The Authors. Published by Blue Eyes Intelligence Engineering and Sciences Publication (BEIESP). This is an open access article under the CC BY-NC-ND license (http://creativecommons.org/licenses/by-nc-nd/4.0/)

\section{INTRODUCTION}

W ater scarcity in Egypt is a major challenge which is increasing year by year. That's because the water demand of the different sectors is increasing while the share of Egypt from Nile River is fixed at 55.5 BCM [1], While the demand is about $72.4 \mathrm{BCM}$ [2]. The Nile is the main source of Egypt's water budget and developments in the Upper Nile threaten to decrease its supply. The expanding population of Egypt creates an ever-growing pressure on the government to provide new land reclamation areas. In addition, public water supply and industrial water requirements are increasing at the expense of agricultural water use [3]. Egypt, an arid country at the end of the longest river in the world, has a negative water balance. Its annual supply of water from the Nile, rainfall along the Mediterranean Coast, and deep groundwater amounts to approximately 57.7 billion cubic meters. But each year, the farms, industries, and people of Egypt use around 72.4 billion cubic meters of water. In Egypt, the reuse of agricultural drainage water provides an integral supplement to the water supply increasing the country's available water resources by $20 \%$ [2]. Reuse of drainage water is essential nonconventional water management strategies in Egypt to optimize the water use efficiency. In the Nile Delta, a considerable number of reuse pump stations (RPSs) are distributed along the main drains network already decades ago. Some of RPSs are still working while others are stopped due to quality problems in canal reaches downstream of these RPSs. However, farmers at the end of the canals are unofficially reusing drainage water to divert drainage water directly to their fields. The major concern about the reuse of agricultural drainage water is the build-up of salts and other trace elements in the root zone to such extent that it interferes with optimal crop growth and causes degradation of shallow aquifers [3]. High soil salinity is a major problem in Egypt in the last few decades [4]. It was addressed with regards to the need to create water supplies for new irrigation projects by reusing of Agri-drainage waters [5] and high-water tables in intensively irrigated areas [4]. Soil salinization is considered ecologically dangerous because it suppresses the growth of many agricultural plants. It also decreases the agricultural productivity in arid and semiarid zones [6]. Moreover, processes of waterlogging, soil compaction, soil salinity and alkalinity are partly too high at different land units [7]. This research aims to assess the water balance in El-Behira governorate to reduce the negative impacts of water scarcity on the crop yield, soil deterioration, evapotranspiration. SIWARE numerical model was used to fulfil the research aim while the results were visualized using geographical

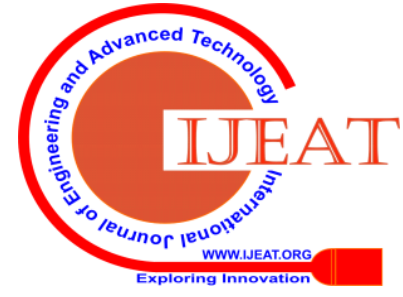




\section{Drainage Water Reuse under Water Scarcity}

information system (GIS).

\section{STUDY AREA}

El-Behira governorate is about $6770 \mathrm{~km}^{2}$, which is part of the Western Nile Delta (WD) and bounded by Rasheed Branch of the Nile from the east, the Mediterranean Sea and Northern lakes from North, the western desert from west and south as in Fig.1. The study area is served with three main canals in the WD that are Rayah El Beheri, El-Mahmoudia and Rayah El- Nasry, which takes their water directly from Rasheed branch. The fields of the study area are irrigated by the distributaries of these main canals. El Behira governorate contains three main drains in the WD which are El-Umom, Edko and Barsiq drains. Moreover, to compensate for the irrigation water shortage in this governorate 10 reuse pump stations (RPS) were distributed along the drains of the Governorate by MWRI as shown in Fig.1 and Fig.2; three of them (RPS) were stopped because of the water quality and health problems.

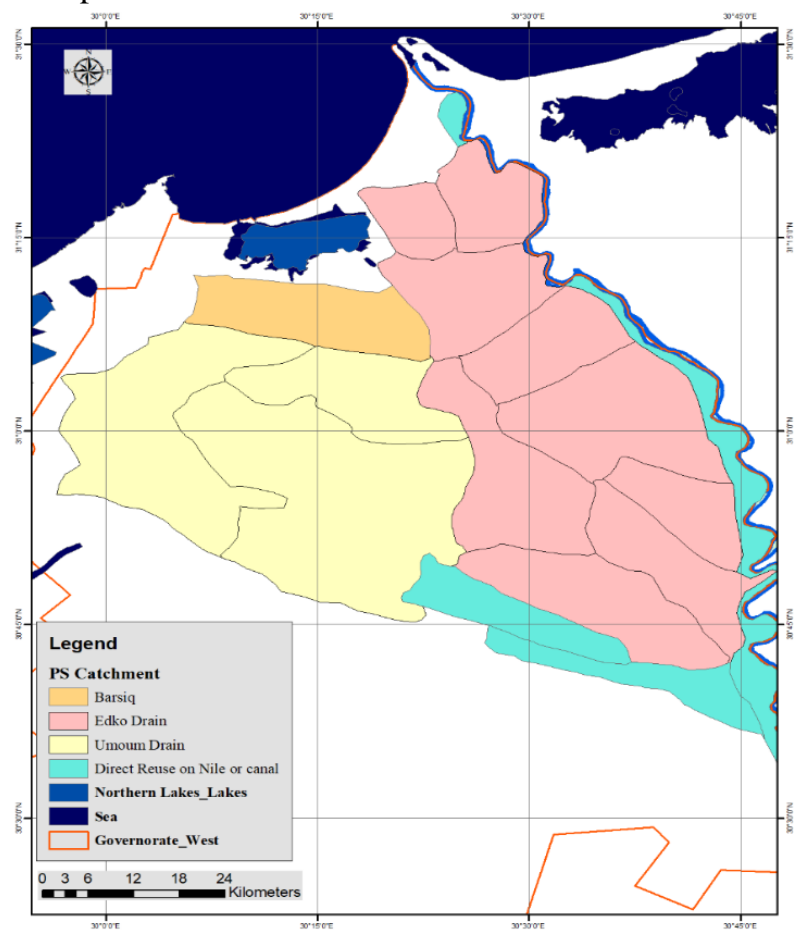

Fig. 1 Drainage pump station catchments in the study area and its' borders with respect to El-Behira Governorate

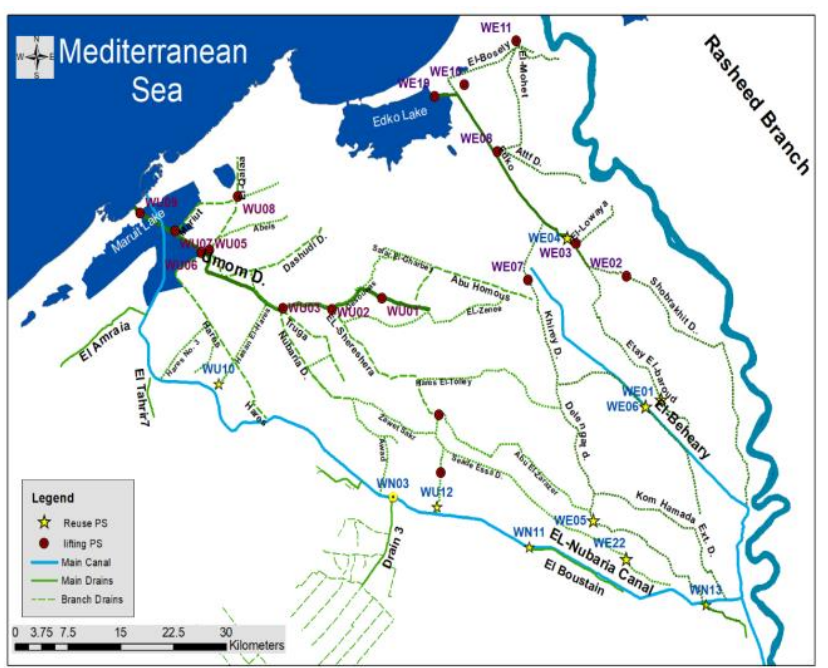

Fig. 2 El-Behira Governorate Canals, Drains, Drainage pump stations and Reuse locations.

\section{METHODOLOGY}

In order to assess the current water uses and soil conditions in the study area (about $6770 \mathrm{~km} 2$ ), SIWARE Model was used to simulate the area considering its characteristics as well as the hydrological and meteorological conditions. The Model was recalibrated and validated using the water and agriculture data sets of two successive years 2014 and 2015. Then, the simulation results were represented using Geographical Information System (GIS) technique which is as a vital tool for decision support.

The program package SIWARE (Simulation of Water management in the Arab Republic of Egypt) has been developed and calibrated for applications on a national and regional level in Egypt [4]. The model was calibrated during the Enhanced Water Resources Management Project (EWRMP) in the year 2014. SIWARE simulates effects of water management strategies and alternatives under arid conditions [5]. In the model applications, the supply rate to the major irrigation canal intakes is fully controlled, and the areas grown with certain crop pattern can be limited [6].

SIWARE model consists of four main modules as shown in Fig.3 each one with special functions [6]. In SIWARE model, the study area is divided into sub-areas, called Calculation Units (CU); each CUs have the same soil type. Also, canals are divided into nodes, while drains are divided into sections, where each CU takes water from one node and drains into one section. The farmer behavior was also considered also in the model as if the freshwater was not enough; the farmer would irrigate his field from the nearest water source as drains, which is called unofficial reuse. Fig.4 displays the mechanism of SIWARE Model.

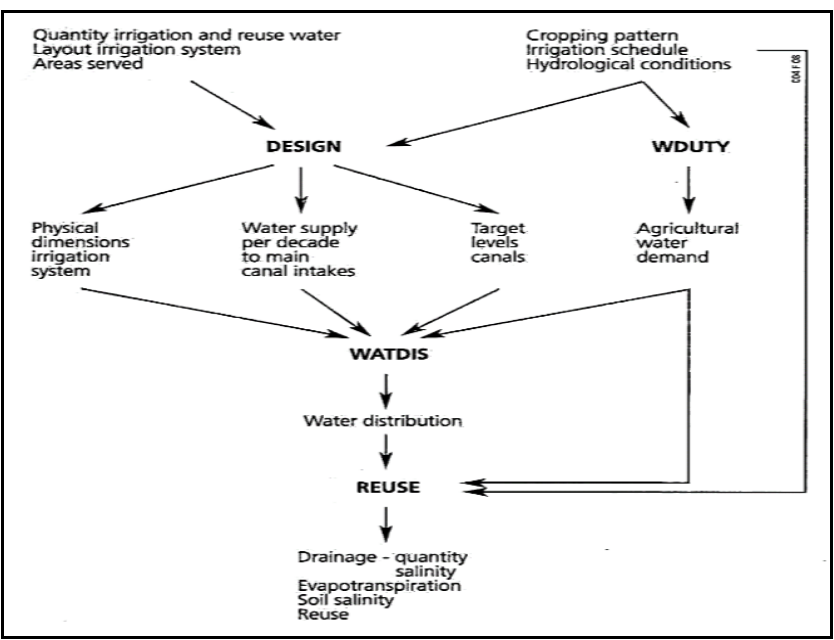

Fig. 3 Modules of SIWARE and inputs of each module [6]
Published By:

Blue Eyes Intelligence Engineering 


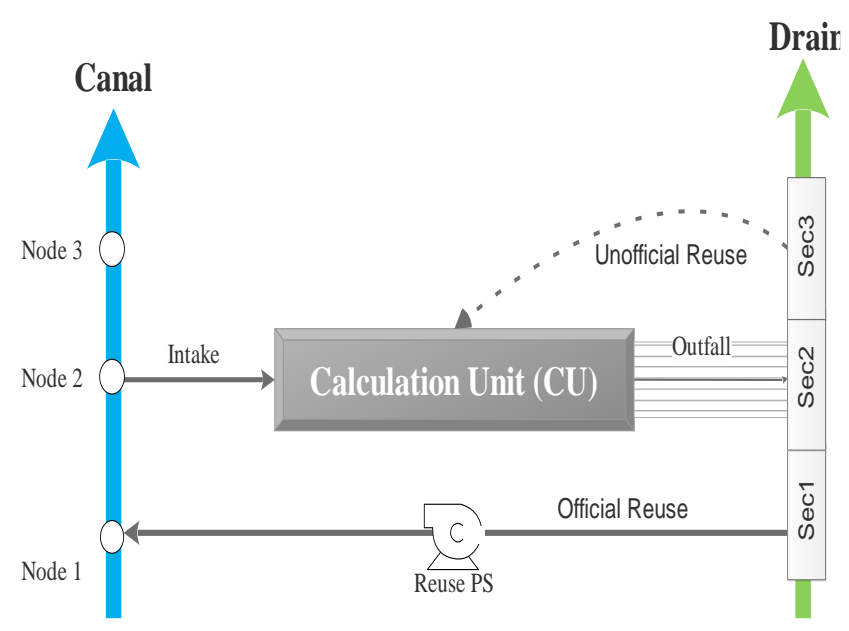

Fig. 4 SIWARE model mechanism

\section{DATA COLLECTION}

In order to apply SIWARE Model on El Behira governorate, all required data were collected covering meteorological and hydrological conditions, soil types, canals and drains catchments, water duties, crop pattern, water and soil salinity, etc. Following the mechanism of SIWARE, the study area (El-Behira Governorate) was divided into 74 Calculation Units (CUs).

Remote sensing techniques were used to classify the land cover especially the vegetated areas. Three Landsat images in year 2014 were downloaded from USGS earth explorer to cover the study area as shown in Fig.5. Moreover, Fig.7 shows the total and the irrigated area of each CU as a fraction of the gross area of each $\mathrm{CU}$ as measured from remote sensing images (see Fig. 6)

Meteorological daily data were collected for reference Evapotranspiration (Eto) and Precipitation (P) using World Association for Public Opinion Research Database [WAPOR] [7]. WAPOR database uses remote sensing images to calculate the climate variables. In SIWARE model, the Nile Delta is divided into three climatic regions: Northern Delta (ND), Middle Delta (MD) and Southern Delta (SD). As the study area lies in the Northern and Middle Delta, Table I tells the maximum and minimum values of ETo and P for the two regions for in 2014. Fig.7 shows the cultivated area as a percentage of the total area in 2014. It can be noticed that the cultivated area is about $89 \%$ of the total study area. The code numbers of the calculation units given in Fig. 7 are according to the code numbering system of the calculation units used in the database of the whole Nile Delta.

For Crop pattern, the data was collected according to the Governorate scale [8], then it was downscaled into CUs scale. In the study area, ten main crops are cultivated: Cotton, Fruits, Maize, Rice, Wheat, long and short Berseem and Vegetables (winter, summer and Nili). Fig.8 shows the cultivated area for each season in percentage of total cultivated area of the year for El_Behira governorate of year 2014.

The officially reused water quantity and salinity were collected from DRI report of year 2015 [9]. About five working reuse PS serve the study area where the total quantity of the officially reused water in the study area were $0.258 \mathrm{BCM} / \mathrm{yr}$.
The irrigation water quantities of the main canals (e.g., El Rayah El Beheiry, El Rayah El Naseri and El Mahmodia canal) and the total amount of the Nile water supply to the whole delta were collected from MWRI (Planning Sector) that presents the decadal data collected from MWRI and also the fractional decadal data for the main canals in the WD in each month and Decade. The input data of the model was in as a decadal fraction of the total water supply to the WD and the total water supply that enters the whole WD.

Table I The Meteorological data needed for SIWARE downloaded from WAPOR database for each Region in the Nile delta [WAPOR] [7]

\begin{tabular}{|r|l|l|l|}
\hline \multirow{2}{*}{ Zone } & & Eto $(\mathrm{mm})$ & $\begin{array}{c}\text { Precipitation } \\
(\mathrm{mm})\end{array}$ \\
\hline \multirow{2}{*}{$N D$} & Max & 7.39 & 1.23 \\
\cline { 2 - 4 } & Min & 2.09 & 0.01 \\
\hline \multirow{2}{*}{$M D$} & Max & 8.39 & 0.00 \\
\cline { 2 - 4 } & Min & 1.86 & 0.00 \\
\hline \multirow{2}{*}{$S D$} & Max & 9.28 & 0.38 \\
\cline { 2 - 4 } & Min & 1.81 & 0.17 \\
\hline
\end{tabular}

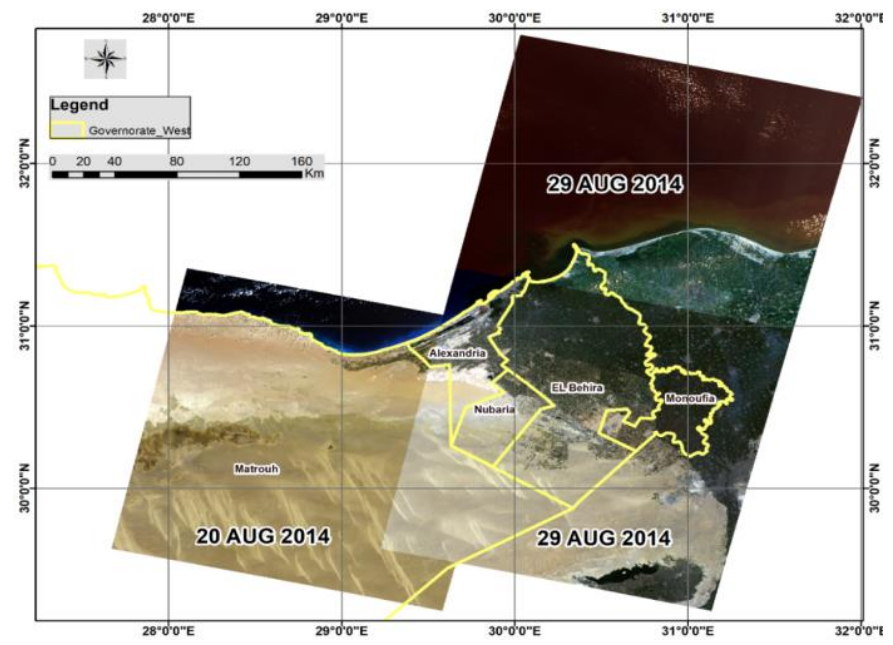

Fig. 5 True color three Landsat image that covers the WD in 2014

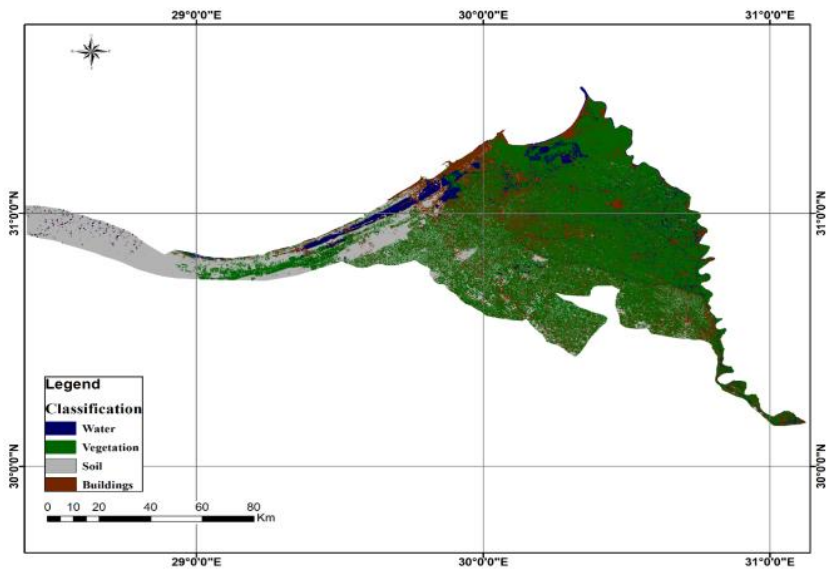

Fig.6 the classified land cover image in WD (August 2014) 


\section{Drainage Water Reuse under Water Scarcity}

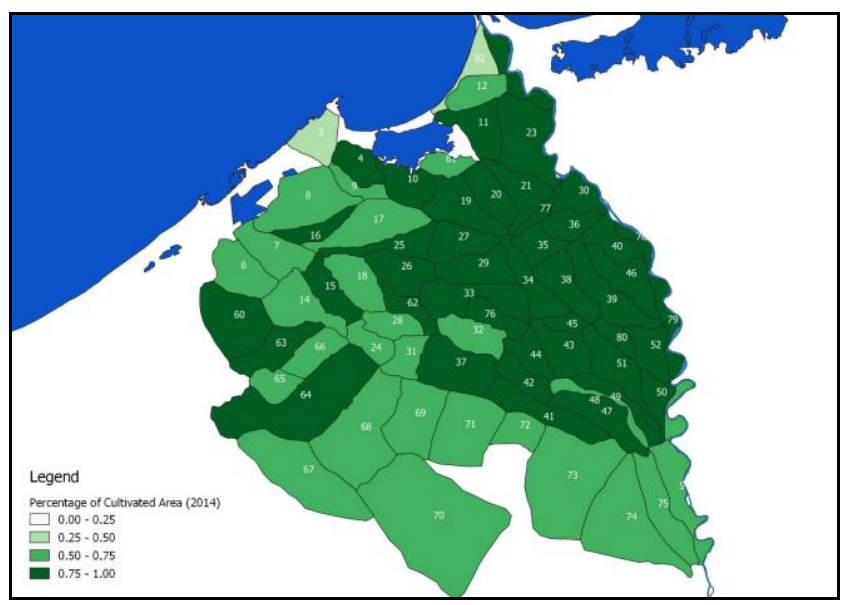

Fig.7 The ratio between the cultivated Area to the total area on CUs for year 2014

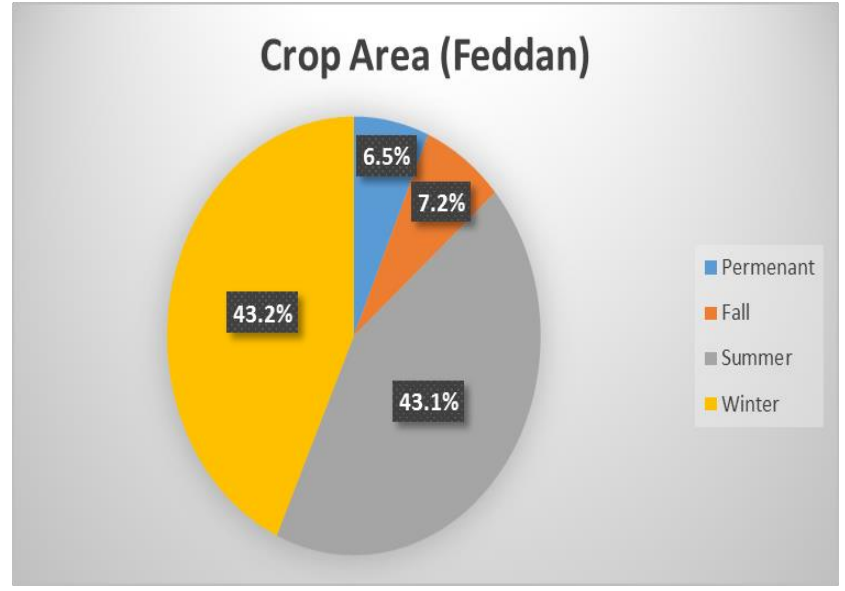

Fig.8 Percentage of cultivated crops in behira governorate for the re-calibration year [8]

\section{RESULT AND DISCUSSION}

\section{A. Calibration and Validation}

The model was calibrated for year 2014 which is considered as a base year. The calibration was carried out in the main canals discharge data using two statistical tests that Classifies the simulation results into four classes (very good, good, satisfactory and unsatisfactory) as in Table I. The first test is (NSE) which is a normalized statistic that determines relative magnitude of the residual variance ("noise") compared to the measured data variance ("information") and it's calculated as in (1). The second test is (RSR) that standardizes RMSE using the observations standard deviation, and it combines both an error index where it's calculated as the ratio between RMSE and standard deviation of measured data as in (2). [10] $N S E=1-\left[\frac{\sum_{i=1}^{n}\left(Y_{i}^{o b s}-Y_{i}^{\text {sim }}\right)^{2}}{\sum_{i=1}^{n}\left(Y_{i}^{o b s}-Y_{i}^{\text {mean }}\right)^{2}}\right]$

$R S R=\frac{R M S E}{S T D E V \text { obs }}=\frac{\sqrt{\sum_{i=1}^{n}\left(Y_{i}^{\text {obs }}-Y_{i}^{\text {sim }}\right)^{2}}}{\sqrt{\sum_{i=1}^{n}\left(Y_{i}^{\text {obs }}-Y_{i}^{\text {mean }}\right)^{2}}}$

Where $\mathrm{Y}_{-} \mathrm{i}^{\wedge}$ obs is the observed value, $\mathrm{Y}_{-} \mathrm{i}^{\wedge}{ }^{\wedge}$ sim is the simulated value, $\mathrm{Y} \_\mathrm{i} \wedge$ mean is the mean of observed data, and $n$ is the total number of observations. (Moriasi et al. 2007)

The two tests were conducted on the the canals of El Behira governorate and its' performance were Very good and good for all results in the calibration and verification years. Fig. 9 and Fig. 10 shows the canals simulated and measured discharges on year 2014 and the validation years (2015 and 2016) for the main and secondary canals in El Behira Governorate.

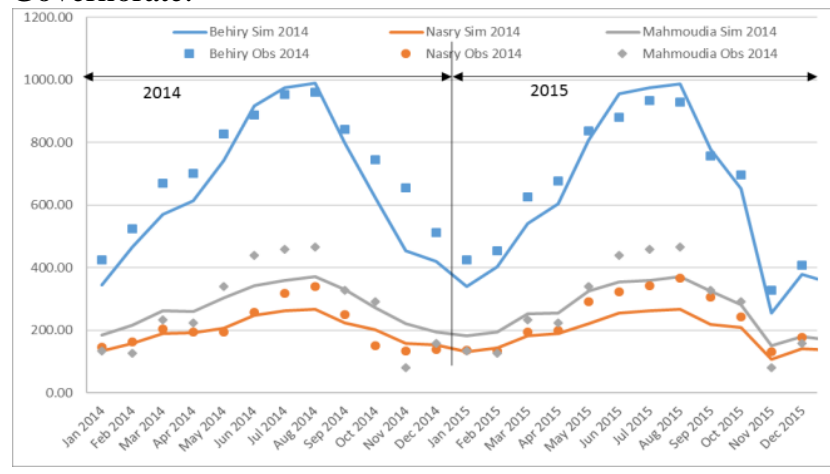

Fig.9 Observation Versus simulation discharges of main canals intakes for years 2014 and 2015 that are used in calibration and validation of the model

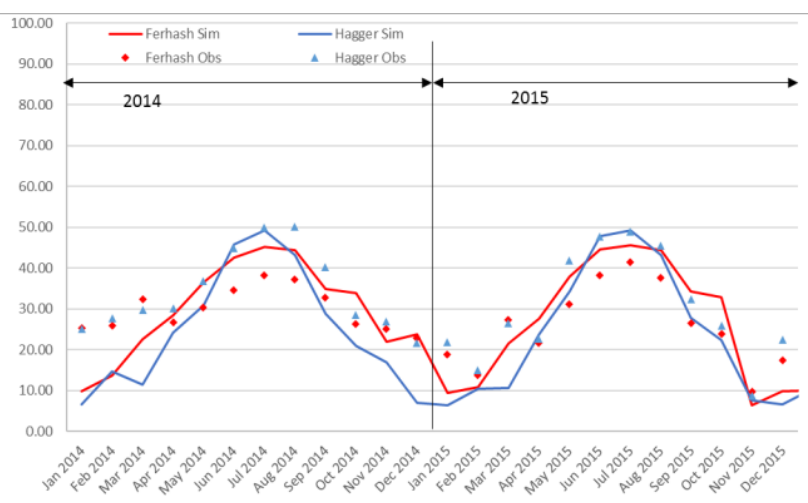

Fig.10 Observation Versus simulation discharges of secondary canals intakes for years 2014 and 2015 that are used in calibration and validation of the model

\section{B. Simulation Results of Intake Discharges from Main} Canals

Fig.11 and Fig.12 show the simulation results of the intake fresh water discharges from main canals and the branch canals that feeds El Behira Governorate.

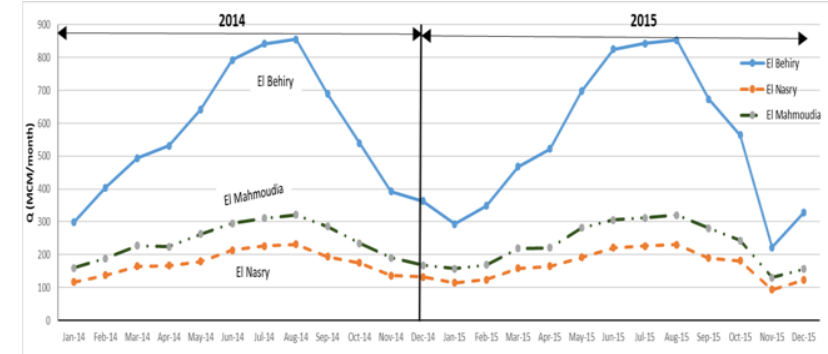

Fig.11: Simulation results of the intake discharges of main canals (Rayah El Behiry, Rayah El Nasry, El and El Mahmoudia Canal) in El Behira Governorate

Published By:

Blue Eyes Intelligence Engineering 


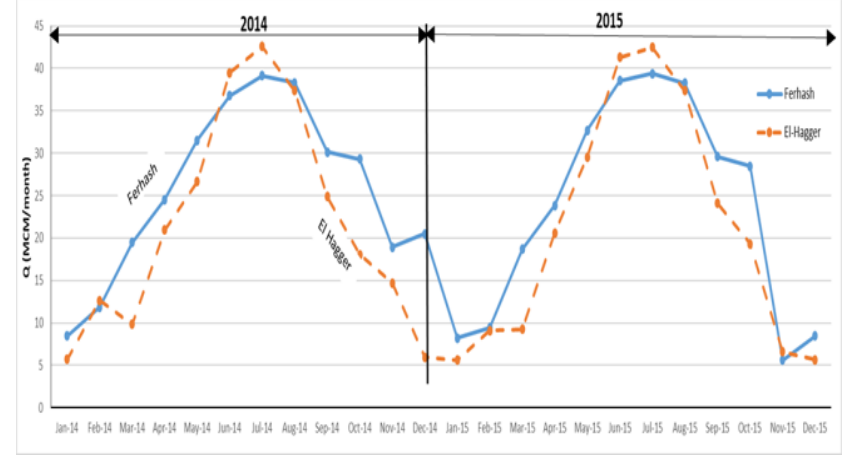

Fig 12: Simulation results of the intake discharges of Secondary canals (Ferhash and El Hagger Canals) in El Behira Governorate

\section{Simulation Results of Drainage Water}

Fig.13 and Fig.14 present the spatial distribution of the unofficial reuse of drainage water quantities on year 2014 and 2015. Due to the need for irrigation water at the end reaches of the distributary canals, the farmers unofficially extract water from the nearest drain to cover the shortage of irrigation requirements of their lands. The simulated amount of the unofficial reuse in the whole study area for year 2014 and 2015 is about 0.811 and $0.870 \mathrm{BCM} / \mathrm{yr}$ relatively. According to the simulation results, it was found that the unofficial reuse in El Behira Governorate were about 9\% and $10 \%$ of the simulated fresh water supply in the Area in both year 2014 and 2015. Additionally, the unofficial reuse of drainage water in year 2015 increased by about $7.3 \%$ than year 2014. Also, the total simulated unofficial reuse amount is about 3 times of the official reuse in the study area [9].

\section{Impacts on the Crop Water Use (ET)}

Fig.15 shows the spatial distribution of the simulated Evapotranspiration (ET) in the study area on years 2014 and 2015. It can be noticed that the crop water use in 2015 is smaller than that of 2014 which happened due to the lack of the fresh water supply and official reused drainage water. The SIWARE model results show that the crop water use is about $77 \%$ and $76 \%$ of the simulated fresh water supply in the whole Area in both year 2014 and 2015. Additionally, the simulated ET for the Meteorological region MD (middle delta) showed the most significant difference between year
2014 and 2015 where Et of year 2015 is less than Et of year 2014 by $15.5 \%$

\section{E. Impacts on Salinity (EC) \\ - Unofficial Reuse Water Salinity}

Fig.16 shows the spatial distribution of the simulated Unofficially Reused Water Salinity classified according to [11] in El Behira Governorate (year 2014 and 2015); where the Unofficial reuse salinity ranged between 0.00 to 5.5 $\mathrm{dS} / \mathrm{m}$. the Unofficially reused water salinity increases in the Northern parts of El Behira Governorate which could be because of the salt water intrusion of the Mediterranean sea in addition to the decreased water quality of drainage water at the end of drains. Additionally, the unofficial reused drainage water salinity is about 3 times that of the irrigation water.

- Drainage Water Salinity

Fig.17 shows the spatial distribution of the simulated Unofficially Reused Water Salinity classified according to (Hopkins et al. 2007) in El Behira Governorate (year 2014 and 2015); where the Unofficial reuse salinity ranged between 0.00 to $5.5 \mathrm{dS} / \mathrm{m}$. the Unofficially reused water salinity increases in the Northern parts of El Behira Governorate which could be because of the salt water intrusion of the Mediterranean sea in addition to the decreased water quality of drainage water at the end of drains. Additionally, the the unofficial reused drainage water salinity is about 3 times that of the irrigation water.

- Soil Salinity

The unofficial reuse affects directly the soil salinity as the farmers are forced to use drainage water with high salinity to irrigate their fields. This causes the accumulation and build-up of salts and causes soil deterioration. Fig.18 shows the spatial distribution of soil salinity, classified according to [12]; where soil salinity ranges between Low and Medium salinity according to [12]. In addition, the higher salinities could adversely affect the crop yield and quality as shown in Fig.19.

Table- I General Performance Ratings for recommended statistics for monthly time step [10]

\begin{tabular}{|c|c|c|}
\hline Performance Rating & RSR & NSE \\
\hline Very Good & $0.00 \leq \mathrm{RSR} \leq 0.50$ & $0.75<\mathrm{NSE} \leq 1.00$ \\
\hline Good & $0.50<\mathrm{RSR} \leq 0.60$ & $0.65<\mathrm{NSE} \leq 0.75$ \\
\hline Satisfactory & $0.60<\mathrm{RSR} \leq 0.70$ & $0.50<\mathrm{NSE} \leq 0.65$ \\
\hline Unsatisfactory & $\mathrm{RSR}>0.70$ & $\mathrm{NSE} \leq 0.50$ \\
\hline
\end{tabular}




\section{Drainage Water Reuse under Water Scarcity}
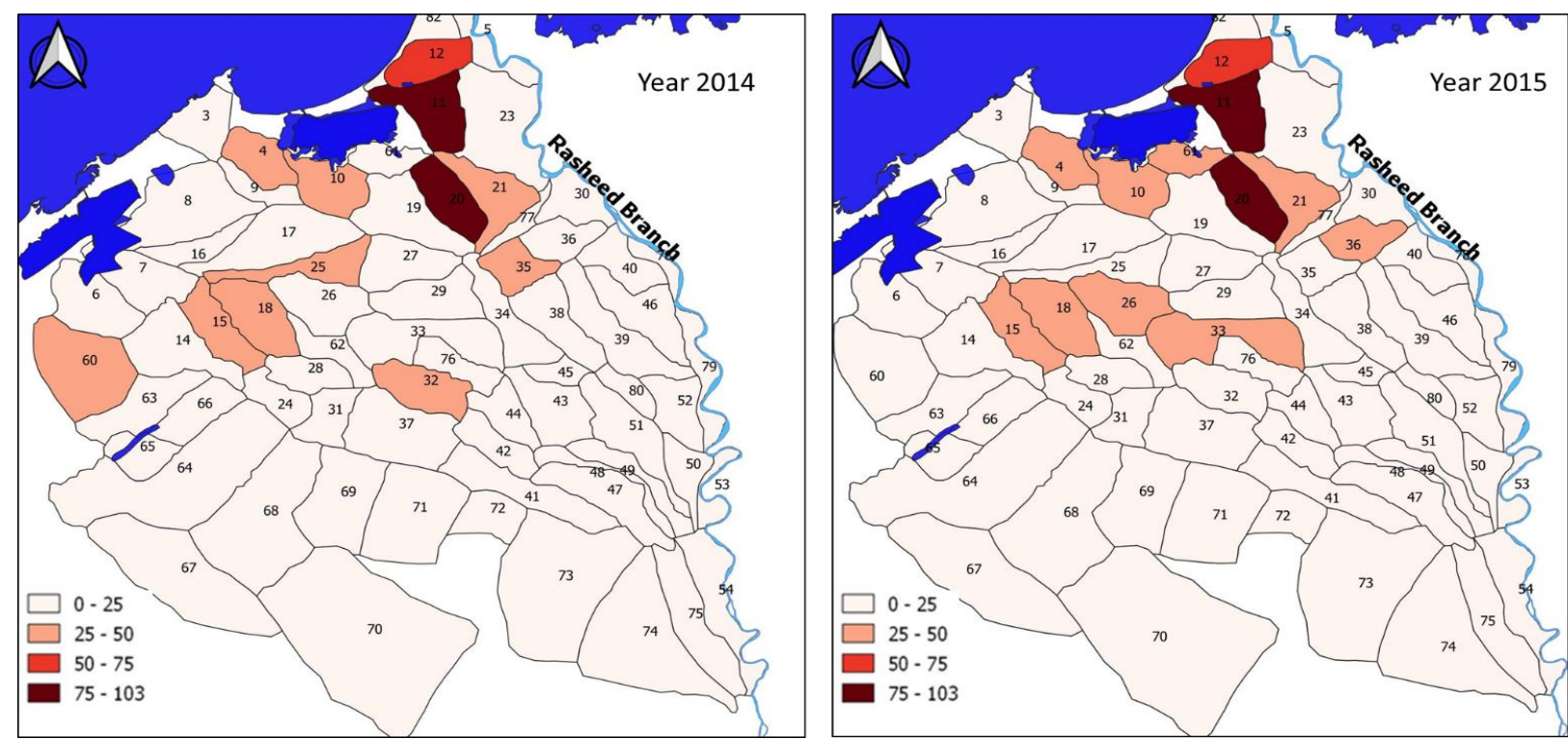

Fig.13: the spatial distribution of the simulated unofficial reuse (MCM/YR) (year 2014 and 2015)
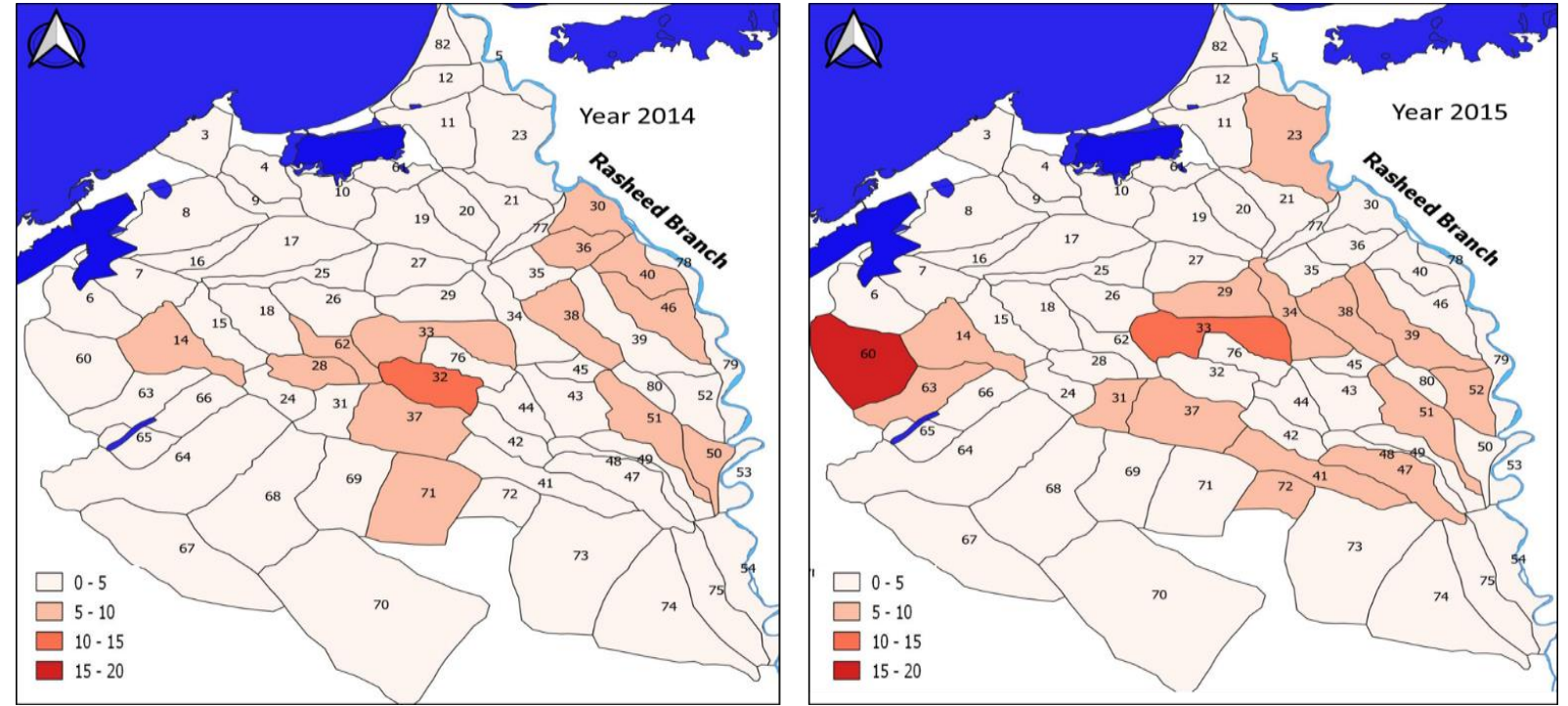

Fig.14: The spatial distributions of the simulated official reuse (MCM/YR) (year 2014 and 2015)
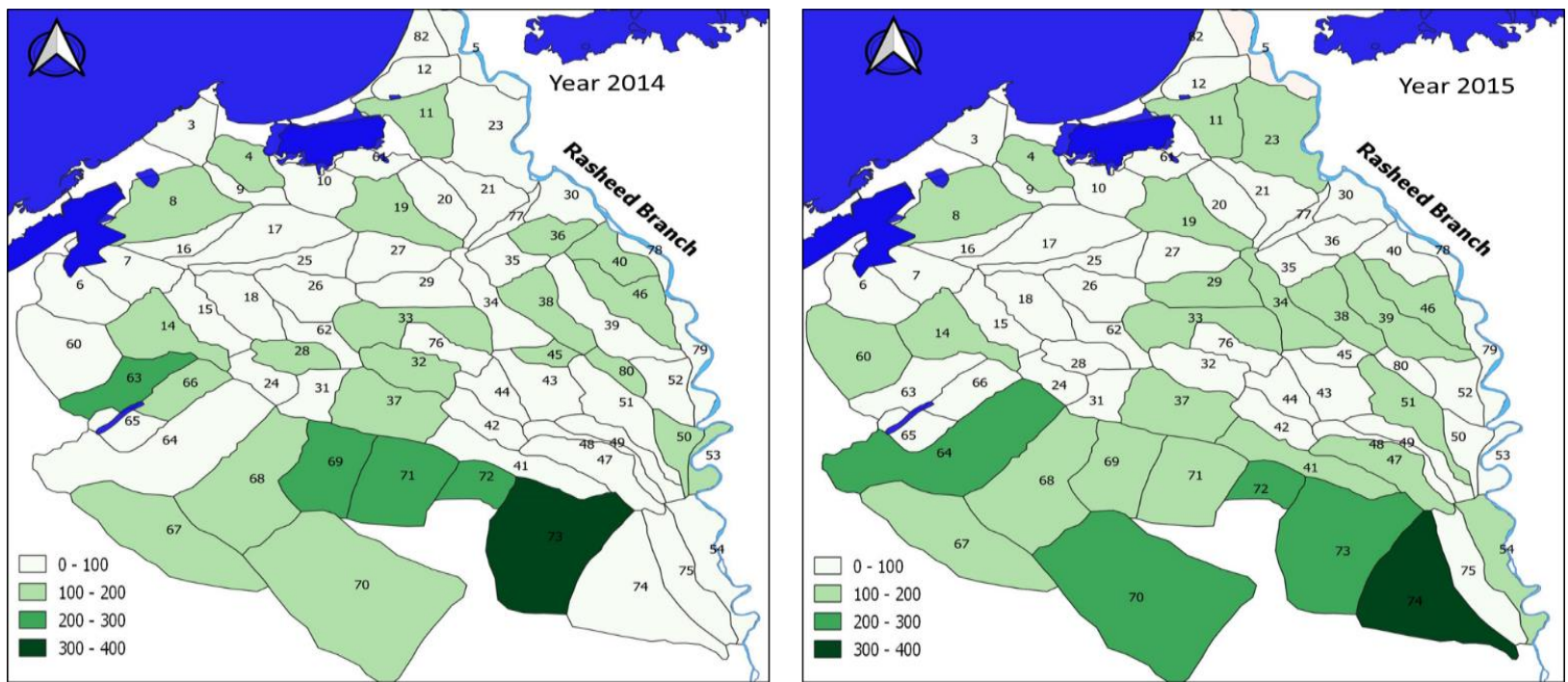

Fig.15: Spatial distribution of the simulated Evapotranspiration (ET) (MCM/YR) in El Behira Governorate (year 2014 and 2015)

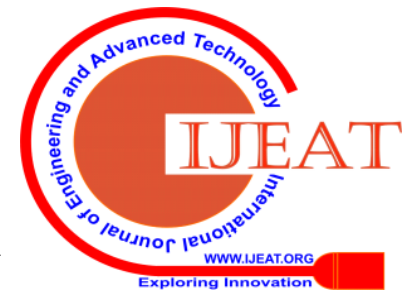



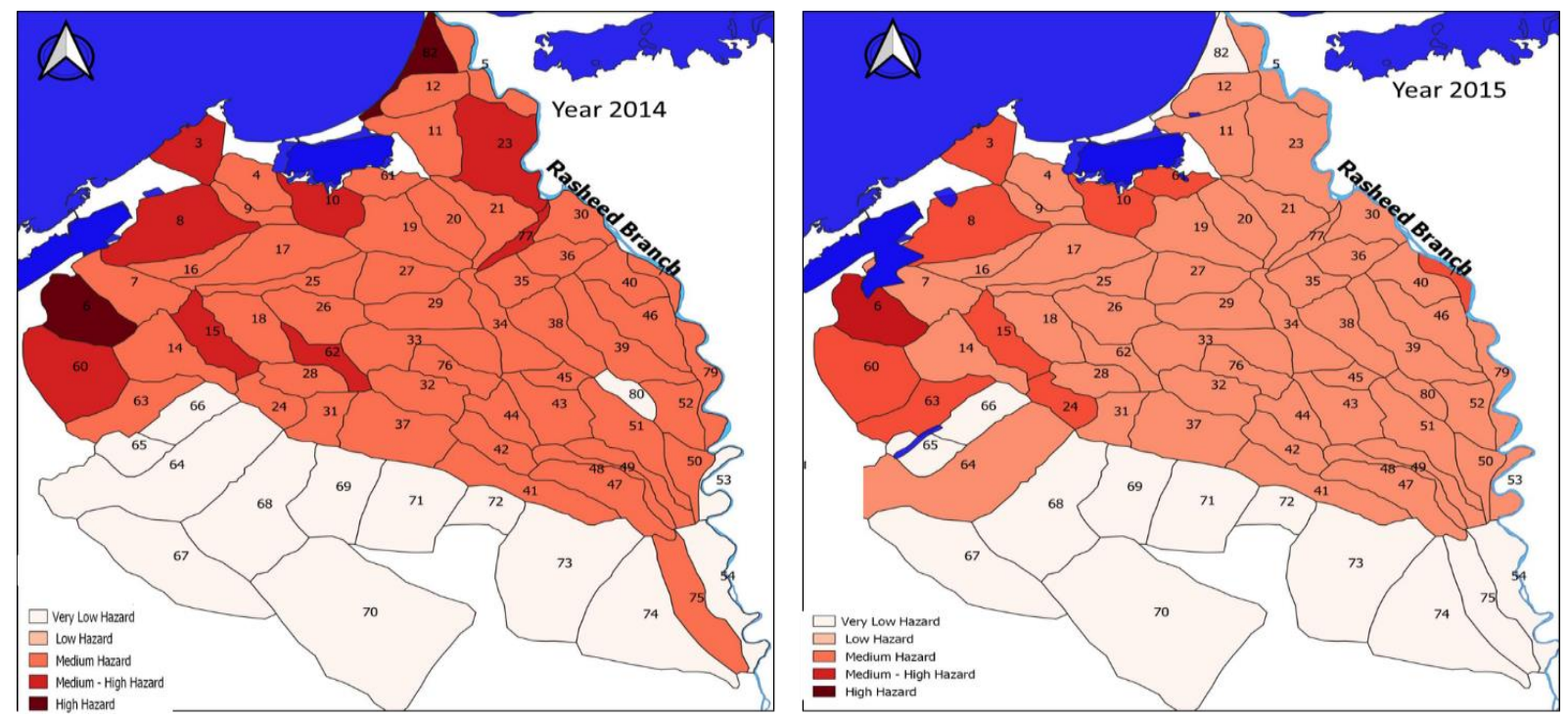

Fig.16: spatial distribution of the simulated Unofficially Reused Water Salinity classified according to [11] in El Behira Governorate (year 2014 and 2015)
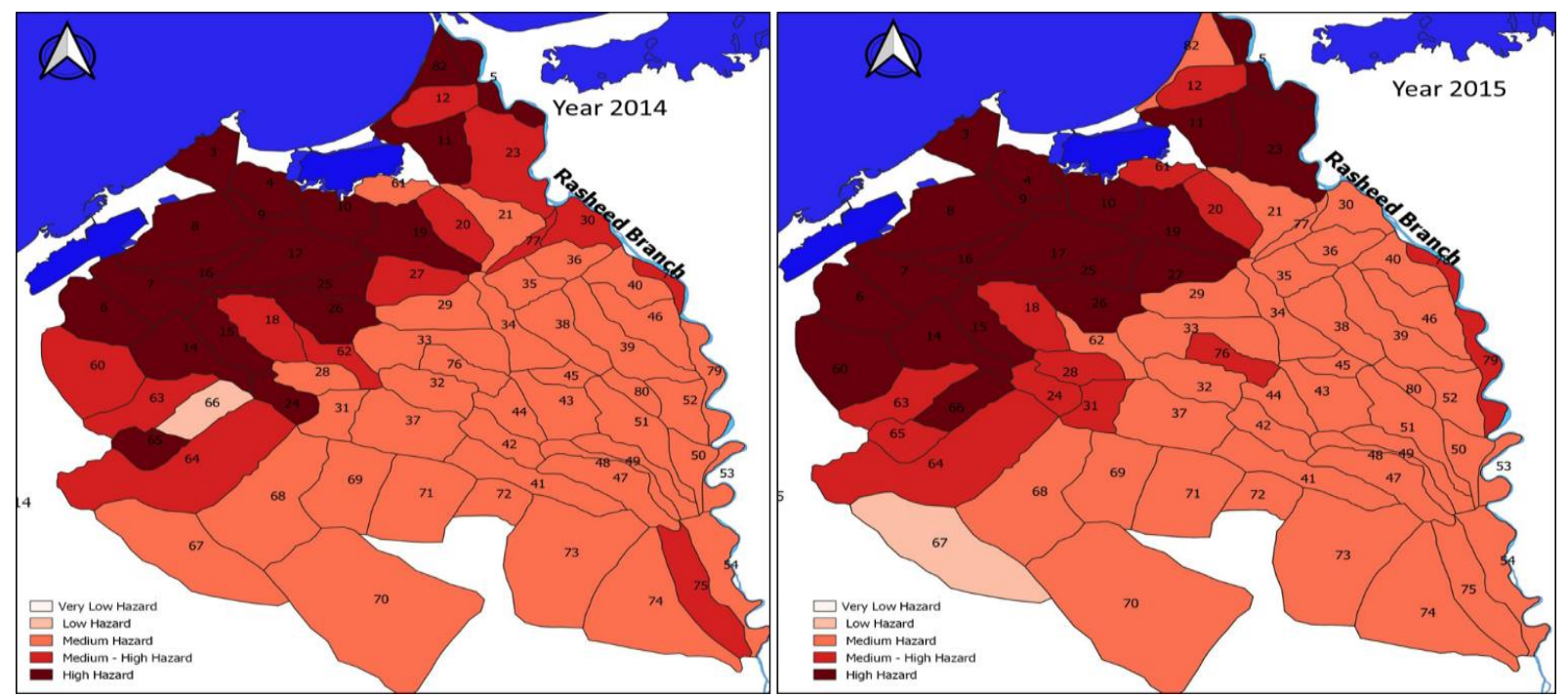

Fig.17: spatial distribution of the simulated Drainage Water Salinity classified according to [11] in El Behira Governorate (year 2014 and 2015)
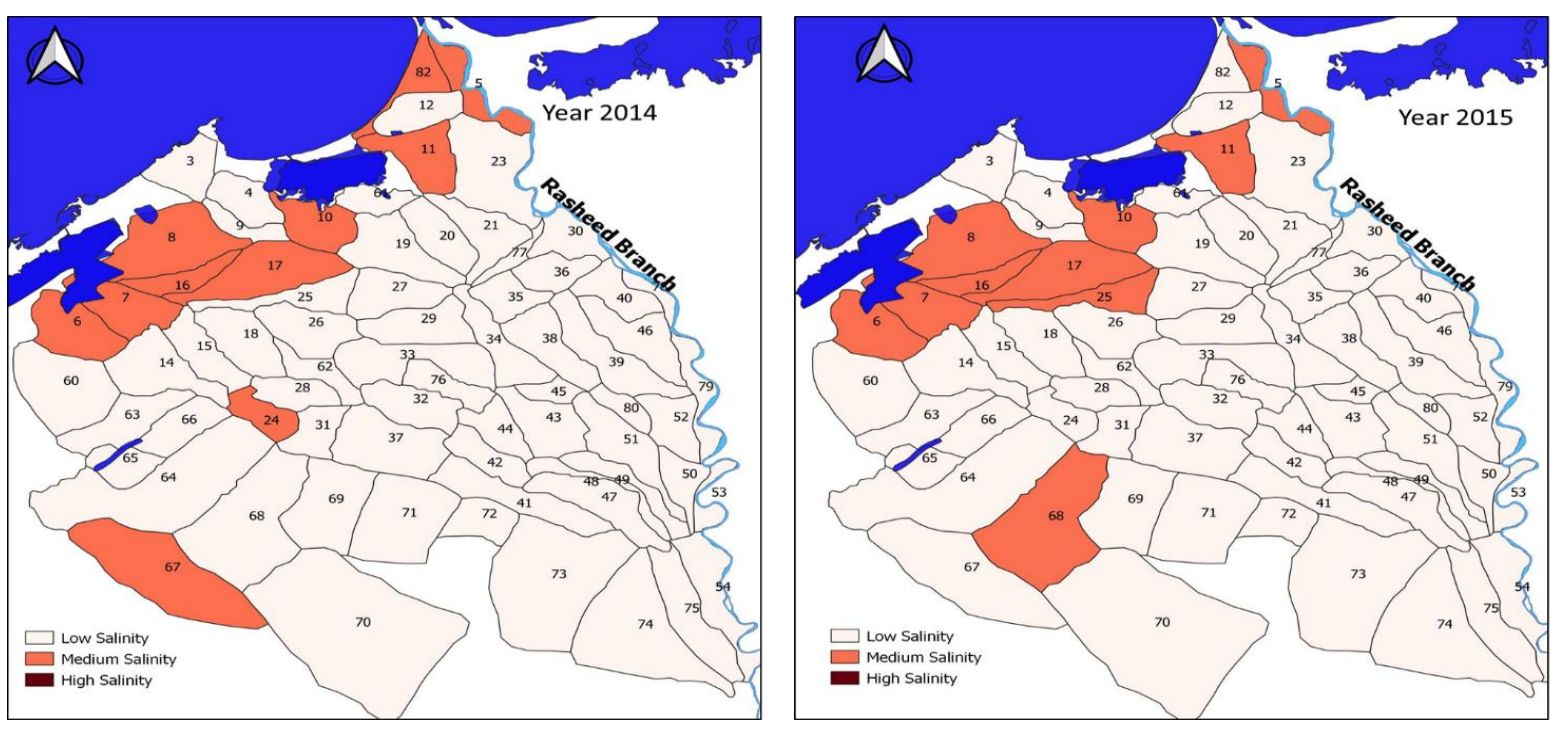

Fig.18 Spatial distribution of simulated Soil salinity classified according to [12] in El Behira Governorate (year 2014 and 2015)

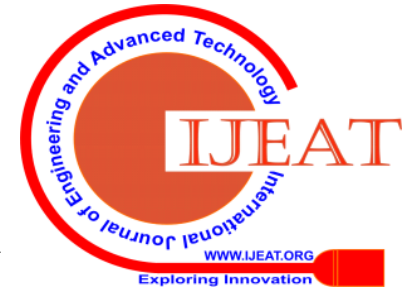




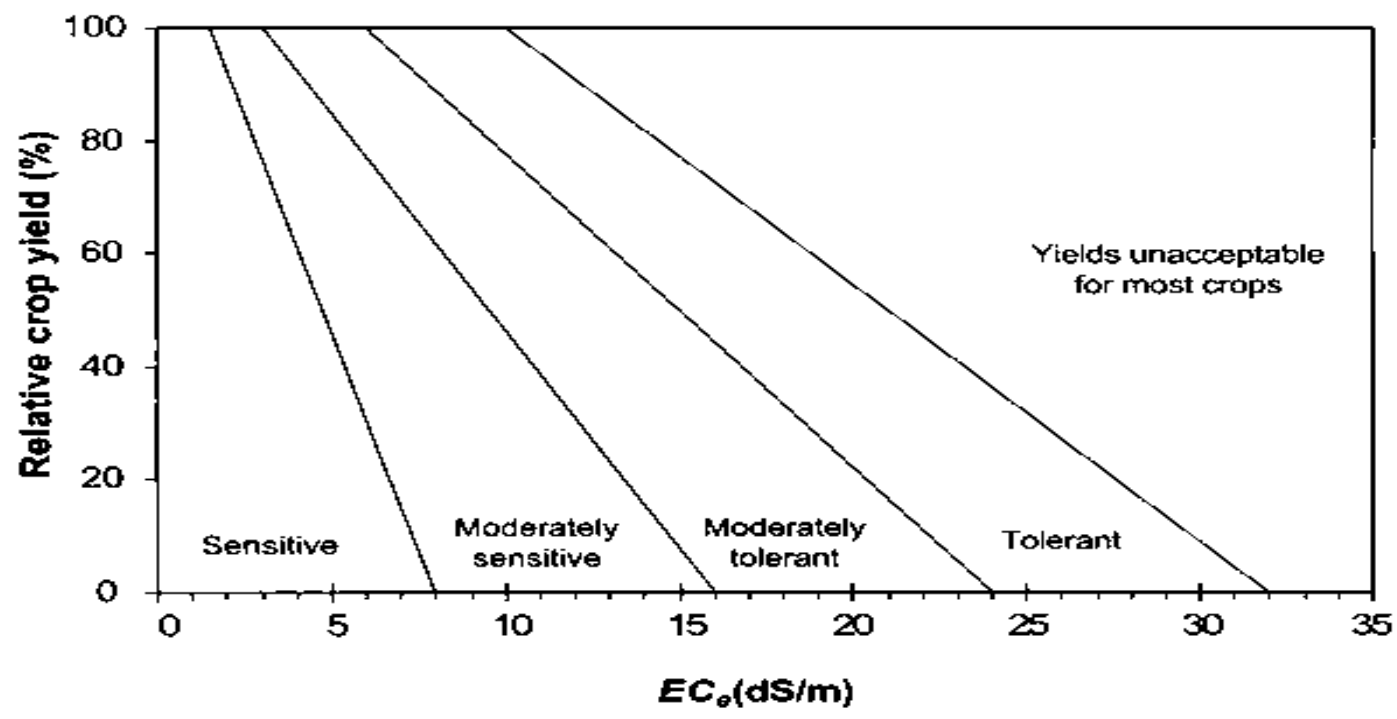

Fig.19 Division for classifying crop tolerance to salinity [13]

\section{CONCLUSION}

SIWARE Model was re-calibrated and validated then it was used to assess the impacts of unofficial drainage reuse on the water use efficiency, crop yield and soil salinity El Behira Governorate located in Western Nile delta for two successive years 2014 and 2015. The model was re-calibrated using data of the base year 2014 then it was validated on year 2015. Two statistical goodness-of-fit coefficients NSE and RSR were used to assess the re-calibration and validation of the model where the results of the model showed good and very good performance with the observations.

The simulation results showed that the study area suffers from water stress which is considered as the main reason for the unofficial drainage water reuse in the study area. According to the simulation results, the unofficial reuse of drainage water in year 2015 increased by about $7.3 \%$ than year 2014. Also, the total simulated unofficial reuse amount is about 3 times of the official reuse in the study area. Additionally, the simulated ET for the Meteorological region MD (middle delta) showed the most significant difference between year 2014 and 2015 where Et of year 2015 is less than Et of year 2014 by $15.5 \%$. Moreover, the simulated soil salinity was between 1 and $4 \mathrm{dS} / \mathrm{m}$, that ranges between low and medium- high salinity hazard, which is affecting negatively the crop yield and quality. While the drained water salinity ranged between 0.64 to $8.0 \mathrm{dS} / \mathrm{m}$. However, the salinity increases in CUs near to Mediterranean Sea which may be the reason of the high salinity of the northern parts of the study area. The unofficial drainage water reuse in the study area causes the rapid soil deterioration, as the salinity of the unofficially drainage water reuse is in the range between medium and high salinities.

Accordingly, it is recommended to generalize the use of the SIWARE model to simulate the Nile Delta region to configure the effects of water shortage on the irrigated areas then studying the different management alternatives to meet the food and energy requirements of Egypt

\section{ACKNOWLEDGMENT}

This research work was partially conducted within the Enhanced Water Resources Management Project (EWRMP) that was financed by Global Environment Facility (GEF). The authors would like to thank Drainage Research Institute DRI and Ain Shams University ASU for their institutional and technical support.

\section{REFERENCES}

1. Ministry of Water Resources and Irrigation, "National Water Resources Plan, Egypt," 2005.

2. J. Barnes, "Geoforum Mixing waters: The reuse of agricultural drainage water in Egypt," Geoforum, vol. 57, pp. 181-191, 2014.

3. B.R. Sijtsma, D. Boels, T.N.M. Visser, C.W J. Roest, and M. F. R. S. (1995). SIWARE Users' Manual version 1.2 (Reuse Report 27). Egypt.

4. DRI, \& Sc-dlo. (1995). "Reuse of Drainage Water in The Nile Delta; Monitoring, Modelling and Analysis". Egypt.

5. C. W. J. Roest, "Regional water distribution in the Nile Delta of Egypt," ILRI Work. water food Secur. Arid ares, no. Figure 1, pp. 61-82, 1999.

6. S.T. Abdel Gawad, M.A. Abdel Khalek, D. Boels, D.E. El Quosy, C.W.J. Roest, P. E. R. and M. F. R. S. (1991). Reuse Report 30 (Vol. 30). Qanater, Cairo.

7. FAO, "Using Remote Sensing in Support of Solutions to Reduce Agricultural Water Productivity Gaps Database methodology: Level 1 Data", May. Rome, 2017.

8. CAPMAS, "Statistical Cropping Areas and the agriculture production 2013/2014 (Reference No. 2014-22122-71).” The Central Agency for Public Mobilization and Statistics (CAPMAS), Egypt, 2016.

9. DRI, "DRI YEAR BOOK", Drainage Water Research Centre, National Water Research centre, 2014/2015

10. D. N. Moriasi, J. G. Arnold, M. W. Van Liew, R. L. Bingner, R. D. Harmel, and T. L. Veith, "Model Evaluation Guidelines for Systematic Quantification of Accuracy in Watershed Simulations," Soil Water Div. Am. Soc. Agric. Biol. Eng., vol. 50, no. 3, pp. 885-900, 2007.

11. B. G. Hopkins, D. A. Horneck, R. G. Stevens, J. W. Ellsworth, and D. M. Sullivan, "Managing Irrigation Water Quality," 2007.

12. D. A. Horneck, J. W. Ellsworth, B. G. Hopkins, D. M. Sullivan, and R. G. Stevens, "M anaging S alt - affected S oils for Crop Production," November, 2007.

13. K. K. Tanji and N. C. Kielen, Agricultural drainage water management in arid and semi-arid areas. Rome: "Food and Agriculture Organization of the United Nations", 2002.

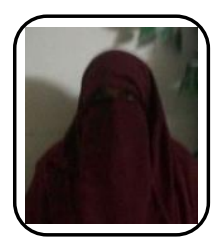

\section{AUTHORS PROFILE}

Aya Abd El-Moneim studied Civil Engineering at Cairo University from 2007 to 2012. She was awarded her Master of Science in Cairo University in year 2016. She is now a Ph.D student at Ain Shams University. 
The topic of her Ph.D research work is "Sustainable Water Resources Management in Western Nile Delta". She is using numerical model techniques along with GIS to fulfil her research. She has accumulated 5 years of experience in "Non-conventional water resources research" while working at DRI. During this period, she has contributed to several research activities that were carried out within national and international activities of the DRI. she is analyzing and assessing drainage Water Quality and Quantity assessment along the three Nile Delta regions, soil samples, ground water logging and seepage problems, subsurface drainage assessment, open drains and subsurface drainage modeling, interpreting and presenting results as well as writing reports. In general, her overall research fields are in managing and assessing wastewater and environmental.

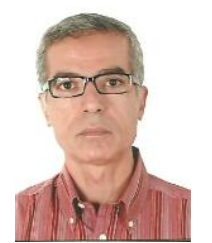

Ahmed A. Hassan studied Civil Engineering at Ain Shams University from 1975 to 1980 . He was awarded his Master of Science in Ain Shams University. He conducted his Ph.D. research work in Technical University Braunschweig in Germany from 1986 to 1988 and was promotion wasin Ain Shams University in 1989. The topic of his Ph.D. research work was "Groundwate Quantity and Quality Modeling”. He developed a 2-D finite element model for simulating groundwater flow and contaminant transport in porous media. Hassan worked as a demonstrator from 1980 to 1984, assistant lecturer from 1984 to 1988, lecturer from 1989 to 1995 and assistant professor from 1995 to 2001 in the Irrigation and Hydraulics Department of the Faculty of Engineering, Ain Shams University. Hassan has been working as Professor of Environmental Hydrology in Ain Shams University since 2001. The published research articles are more

than 60 in the fields of Irrigation, Hydraulics and Hydrology and supervised many of the M.Sc. and Ph.D. candidates in all Egyptian Universities. Prof. Hassan works as a consultant in the fields of Water Engineering and Hydrology.

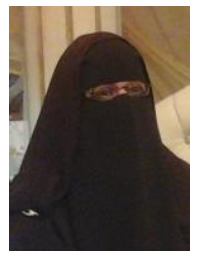

Samia Aboul Fetouh studied Civil Engineering at Ain Shams University from 1997 to 2002. She was awarded her Master and Ph.D. in Ain Shams University. The topic of her Ph.D. research work was "Surface Water Quality Management". She studied the water quality management in Rosetta Branch of river Nile using WASP water quality model, and develop a user friendly (GIS) model using visual basic for application (VBA) in ArcGIS environment. Samia worked as a demonstrator from 2003 to 2007, assistant lecturer from 2007 to 2014, lecturer from 2014 till now in the Irrigation and Hydraulics Department of the Faculty of Engineering, Ain Shams University. She published many research articles in the fields of Irrigation, Water Quality and Hydrology and supervised many of the M.Sc. and Ph.D. candidates in Ain Shams University.

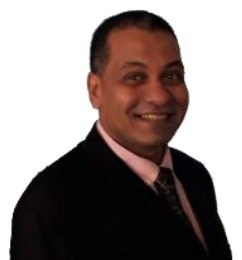

Since 1995, Dr. El Saadi has been working as a researcher for the National Water Research Center [NWRC] of Egypt. Presently, he is Associate Professor and Director of the Technical Office of the President of the NWRC. He supervised and examined several academic theses (Ph.D. and M.Sc.) in the engineering, science and, environmental departments of different Egyptian and multinational universities. Those including Cairo, Ain Shams universities besides Japanese university in Egypt. He participated as an examiner for undergraduate engineering projects of the final year, faculty of engineering, Helwan University, Cairo. He lectured professionals in national and international courses in engineering sciences including water hydraulic and water quality, design of water quality monitoring networks, and reuse of water. $\mathrm{He}$ published several articles and a book chapter in engineering, water and environmental topics in well-recognized journals issued via acknowledged publishers as Elsevier and Springer. Dr. El Saadi has participated as a researcher and coordinator among various national and multinational development projects and research studies within subjects concerning Environmental Engineering, Water Quality Management, Environmental Impacts Assessment, Decision Support System (DSS), Geographical Information System (GIS), and Remote Sensing.During his way to build his carrier, he participated in national and international training courses regarding environmental engineering, statistical analysis, Geographical Information Systems (GIS) and, Technical writing.

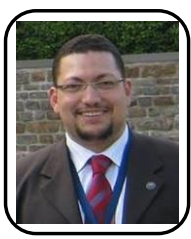

Ahmed Abdallah works currently as the Chief Technical Officer of the Drainage Research Institute (DRI), National Water Research Center in Egypt. He completed his $\mathrm{PhD}$ in Irrigation and Drainage at civil engineering department (2016) from the Faculty of Engineering of El-Mataria, Helwan University in Egypt. He completed his MSc special JICA program in Civil Engineering (2010) from the School of Engineering, Tottori University in Tottori, Japan. His work experience is more than 13 years in environmental and water research especially with remote sensing and GIS techniques while working as a researcher in DRI. He contributed into multiple studies and research projects that have been carried out within national and international scale. Main work Tasks:

- Organize and monitor all technical activities for various DRI research projects and ensure compliance to all objectives and prepare appropriate budgets and coordinate with various staff to ensure required standards.

- Prepare and maintain DRI /NWRC project budgets and ensure compliance to all project schedule.

- Determine the design philosophy and ensure consistency for same on research projects and participate in various events to maintain knowledge on latest technologies and investment.

- Administer and ensure optimal utilization of all DRI resources to increase growth and develop various new products for services to maintain effective growth.

- Monitor and follow up water research equipment and tools and complete all running research projects and studies within the required time-frame and ensure optimal quality standards for same and monitor efficient working of multiple projects.

- Coordinate with DRI researchers, engineers and technicians and achieve all DRI objectives and assist HR department to recruit and train young engineering staff.

- Assist DRI technical departments and coordinate various engineering practices to reduce cost and improve quality of projects.

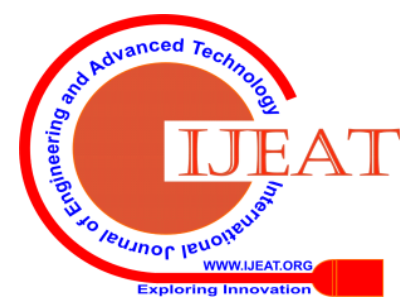

